\title{
A minimum in the latitude variation of spread-F at March equinox
}

\author{
N. Balan ${ }^{1,2^{*}}$, T. Maruyama ${ }^{3}$, A. K. Patra ${ }^{4}$ and V. L. Narayanan ${ }^{4}$
}

\begin{abstract}
This short paper presents the statistics of spread-F occurrence at four low-mid latitude locations $\left(17.0^{\circ} \mathrm{N}, 21.2^{\circ} \mathrm{N}\right.$, $26.5^{\circ} \mathrm{N}$ and $36.5^{\circ} \mathrm{N}$ mag. lat.) in Japan longitude sector $\left(\sim 135^{\circ} \mathrm{E}\right)$ in March to April 2002, 2003 and 2006 (high, medium and low solar activity). The location of a spread-F minimum predicted by theoretical models is identified for the first time. The spread-F minimum occurs at the poleward side of the equatorial ionisation anomaly crest and shifts equatorward from $\sim 25^{\circ} \mathrm{N}$ mag. lat. at high solar activity to below $17^{\circ} \mathrm{N}$ at low solar activity. The corresponding spread- $\mathrm{F}$ maximum occurring on the poleward side of the minimum also shifts equatorward from $\sim 35^{\circ} \mathrm{N}$ (or beyond) at medium solar activity to $20^{\circ}-25^{\circ} \mathrm{N}$ at low solar activity. The spread-F occurrence increases with decreasing solar activity at all locations especially at higher latitudes $\left(>\sim 25^{\circ} \mathrm{N}\right)$ where there is almost no occurrence at high solar activity.
\end{abstract}

Keywords: Low-mid latitude spread-F, Minimum and maximum in spread-F

\section{Introduction}

Earth's ionosphere has a smooth density distribution during daytime when there is production of ionisation. In other words, during daytime when the E-region conductivity is strong, the ionospheric drivers such as electric fields and neutral winds and their fluctuations cannot destabilise the ionosphere. But after sunset when the Eregion conductivity becomes weak, the drivers can destabilise the ionosphere and generate plasma irregularities of various scale sizes that manifest as spread-F (Booker and Wells 1938) and plasma bubbles (Woodman and La Hoz 1976) causing scintillations in communication signals (Aarons 1993). The irregularities occurring at low and mid latitudes have been studied widely using various experimental and theoretical modelling techniques for over 75 years to understand their science and variability and for mitigating their adverse effects on communication and navigation; for recent reviews, see Bowman (1990), Aarons (1993), Patra 2008, Woodman (2009), Kelley et al. (2011), and Yokoyama and Stolle (2017). The studies are to be continued for a better understanding of the generation

\footnotetext{
* Correspondence: balan.nanan@yahoo.com

${ }^{1}$ Institute of Geology and Geophysics, Chinese Academy of Sciences, Beijing 100029, China

${ }^{2}$ Institute of Space Earth Environment, Nagoya University, Nagoya, Japan Full list of author information is available at the end of the article
}

and growth of the irregularities and their day-to-day variability to reach a level of forecasting capability.

The spread-F and plasma bubbles at equatorial latitudes where the geomagnetic field lines are horizontal are thought to originate through the Rayleigh-Taylor (RT) instability mechanism (Dungey 1956; Scannapieco and Ossakow 1976; Jayachandran et al. 1993). The main driver that destabilises the ionosphere at post-sunset hours is the pre-reversal strengthening of the eastward electric field (e.g. Heelis et al. 1974; Eccles et al. 2015), which causes the pre-reversal enhancement of the vertical upward $E \times B$ plasma drift velocity $\mathrm{Vz}$ referred as PRE (e.g. Fejer et al. 1979; Namboothiri et al. 1989; Balan et al. 1992; Huang and Hairston 2015). The irregularities have a linear growth rate (Ossakow 1981):

$$
\gamma=(1 / H)\left(g / \nu_{\text {in }}+\mathrm{Vz}\right)-\beta
$$

The first and second terms are the gravitational and cross-field instability growth rates, $\beta$ is the recombination rate, $H$ is the electron density scale height, $g$ is the acceleration due to gravity, and $v_{\text {in }}$ is ion-neutral collision frequency. The irregularities originating at the equatorial bottom-side F-region rise to the topside as plasma bubbles (Scannapieco and Ossakow 1976) and extend along the field lines to higher latitudes especially at high solar activity when PRE is strong. 
Modelling studies of the growth rate have predicted a low latitude minimum. For example, Maruyama (1990) who modelled the growth rate of both the gravitational and cross-field $(E \times B)$ instability modes using flux tube integrated values (without neutral wind) showed that the net instability growth rate at March equinox under medium solar activity $(\mathrm{F} 10.7=120)$ is negative in a narrow latitude region near $18^{\circ}$ mag. lat. At lower and higher latitudes, the ionosphere becomes unstable.

The neutral wind fluctuations known as waves especially gravity waves which are always present and cause fluctuations in the $E \times B$ drift velocity (Balachandran et al. 1992; Abdu et al. 2015) are thought to act as the seed for the onset of the plasma irregularities (e.g. Osaakow, 1981; Sekar et al. 1995). The background neutral wind can also directly influence the growth of the irregularities (e.g. Maruyama and Matuura 1984). At low solar activity and when PRE is absent, the plasma irregularities generally occur at around midnight (e.g. Nishioka et al. 2012). They are thought to be caused mainly by the electric field fluctuations due to atmospheric gravity waves propagating to ionospheric heights easily at low solar activity (e.g. Tsunoda et al. 2010; Patra et al. 2013; Tulasiram et al. 2014; Narayanan et al. 2014a).

Plasma irregularities have also been observed at low and mid latitudes where PRE is absent due to inclined geomagnetic field lines (Bowman 1990 and references therein). Whalen (2002) studied the spread-F occurrence at a chain of stations up to $20^{\circ}$ mag. lat. in American sector. Fukao et al. (1991) and Kelley and Fukao (1991) studied the Fregion plasma irregularities observed by the MU (middle and upper atmosphere) radar. Otsuka et al. (2002), for the first time, observed an identical optical structure at conjugate stations beyond the EIA crests.

The mid latitude plasma irregularities were first thought to be associated with atmospheric gravity waves (e.g. Bowman 1990; Kelley and Fukao 1991) and later with medium-scale travelling ionospheric (atmospheric) disturbances (MSTIDs) (e.g. Saito et al. 2001; Makela and Otsuka 2012). The mechanism that relates the mid latitude plasma irregularities to its source (e.g. MSTID) is the so-called Perkins instability (Perkins 1973; Miller 1997) which takes the form of rising and falling sheets of ionisation when a north-south electric field is present in addition to the east-west field. Hamza (1999) updated the Perkins equations by adding neutral wind. Recent understanding is that the electro-dynamical coupling between the E- and F-regions plays an important role in enhancing the growth rate of Perkins instability (e.g. Tsunoda and Cosgrove 2001; Yokoyama et al. 2008). The instability has a linear growth rate (Tsunoda 2006; Yokoyama and Stolle 2017):

$$
\gamma=(|E| \cos I)[\sin (\theta-\alpha) \sin \alpha] / B H
$$

where $E=E_{0}+U^{\mathrm{F}} \times B$ is total effective electric field with $E_{0}$ being the background field; $U^{\mathrm{F}}$ is F-region neutral wind, $B$ is geomagnetic field of magnitude $\mathrm{B}, I$ is magnetic inclination angle, $H$ is atmospheric scale height including ion-neutral collision frequency, $\theta$ is the angle between $E$ and east direction, and $\alpha$ is the angle between the direction normal to the frontal structure and east direction. A maximum of the growth rate $\gamma$ is expected to occur at the location where $\alpha=\theta / 2$.

As introduced, theoretical models have predicted a low-latitude minimum (e.g. Maruyama 1990) and a midlatitude maximum (e.g. Tsunoda 2006) for the occurrence of plasma irregularities manifested as spread-F in ionograms. The possibility of the minimum has also been indicated by optical observations of MSTIDs (Shiokawa et al. 2002, 2003), which shows a low-latitude limit for their propagation at $\sim 18^{\circ} \mathrm{N}$ mag. lat. at high solar activity (1999), and the limit is found to extend to further lower latitudes at low solar activity (e.g. Narayanan et al. 2014b). However, to our knowledge, the expected minimum and maximum in the occurrence of plasma irregularities have not yet been identified.

This short paper identifies the spread-F minimum and maximum for the first time by analysing the ionosonde data during the March equinox season when the minimum was predicted. The data used are collected at four low- to mid-latitude locations $\left(17.0^{\circ} \mathrm{N}, 21.2^{\circ} \mathrm{N}, 26.5^{\circ} \mathrm{N}\right.$ and $36.5^{\circ} \mathrm{N}$ mag. lat.), referred as low-mid latitudes, in Japan longitude sector $\left(\sim 135^{\circ} \mathrm{E}\right)$ in March to April (or equatorial spread-F season (Aarons 1993) at high, medium and low solar activity (2002, 2003 and 2006). The locations of the spread-F minimum and maximum are found to shift equatorward with decreasing solar activity.

\section{Methods/Experimental}

The study uses the ionosonde data collected at Okinawa $\left(26.7^{\circ} \mathrm{N}, 128.2^{\circ} \mathrm{E} ; 17.0^{\circ} \mathrm{N}\right.$ mag. lat.), Yamagawa $\left(31^{\circ} \mathrm{N}\right.$, $131^{\circ} \mathrm{E} ; 21.2^{\circ} \mathrm{N}$ mag. lat.), Kokubunji $\left(35.7^{\circ} \mathrm{N}, 139.5^{\circ} \mathrm{E}\right.$; $26.5^{\circ} \mathrm{N}$ mag. lat.) and Wakkanai $\left(45.4^{\circ} \mathrm{N}, 141.7^{\circ} \mathrm{E}\right.$; $36.5^{\circ}$ $\mathrm{N}$ mag. lat.) in Japan during March to April 2002, 2003 and 2006. The periods cover high, medium and low solar activity (mean F10.7 =185, 129 and 82) when typical post-sunset EIA crests reach up to $\sim \pm 22^{\circ}, \pm 18^{\circ}$ and \pm $15^{\circ}$ mag. lat. as shown by model calculations (Balan and Bailey 1995; Balan et al. 1997, 2012). The ionosondes at Yamagawa $\left(21.2^{\circ} \mathrm{N}\right.$ mag. lat.) and Okinawa $\left(17.0^{\circ} \mathrm{N}\right.$ mag. lat.) might have fallen at around the northern EIA crest during the evening-night hours in 2002 and 2003, and the crest might not have reached Okinawa (lowest latitude) in 2006. 
The ionograms collected at 15-min intervals are analysed for the occurrence, onset time and duration of spread-F. As shown by the sample ionograms (Fig. 1), the spread-F at Okinawa and Yamagawa is range type and that at Kokubunji and Wakanai is frequency type. The spread-F in these stations are found to be of the same type at all levels of solar activity except for a few cases which are not distinguished in the analysis. Figure 2 shows the statistics of occurrence, onset time and duration of spread-F at all locations in March to April 2002. Figures 3 and 4 are similar to Fig. 2 but for 2003 and 2006. The data are available for all days at all locations except for a gap of 7 days at Wakkanai (02-08 April 2002).

\section{Results}

High solar activity

The spread-F occurrence in the low-mid latitude region at high solar activity (2002; Fig. 2) is not so frequent.
The occurrence also decreases steadily with increasing latitude from $\sim 26 \%$ at Okinawa to $\sim 2 \%$ at Wakkanai, and there is almost no occurrence at latitudes beyond $26.5^{\circ} \mathrm{N}$ (Kokubunji). No spread-F occurred at higher latitudes without a corresponding spread-F at lower latitudes (Okinawa) except for the lone case at the highest latitude (Wakkanai). The spread-F onset at all locations is generally at post-sunset hours $(\sim 21-23 \mathrm{LT})$ except at Okinawa where some cases occurred at post-midnight hours also. On common days of spread-F, the occurrence at higher latitudes in general started at around the same time or slightly after its start at the lowest latitude, and the duration of spread-F is generally longer at lower latitudes (Okinawa and Yamagawa) and shorter at higher latitudes except for the lone case at the highest latitude. The observations therefore indicate that at high solar activity when typical post-sunset EIA crest reaches up to $\sim 22^{\circ} \mathrm{N}$ mag. lat. (Balan et al. 1997), the low latitude minimum of spread-F is located at the poleward side of the EIA

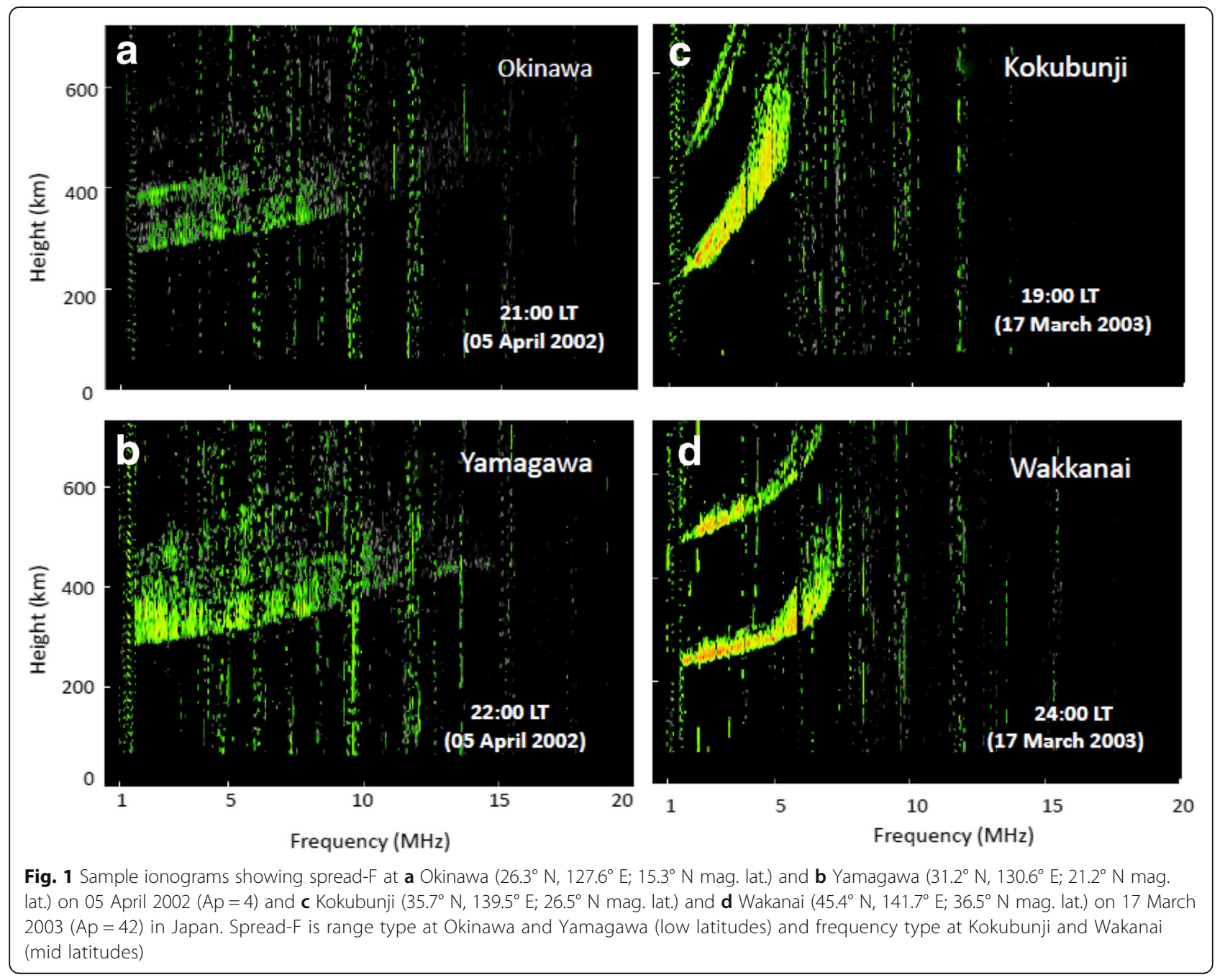




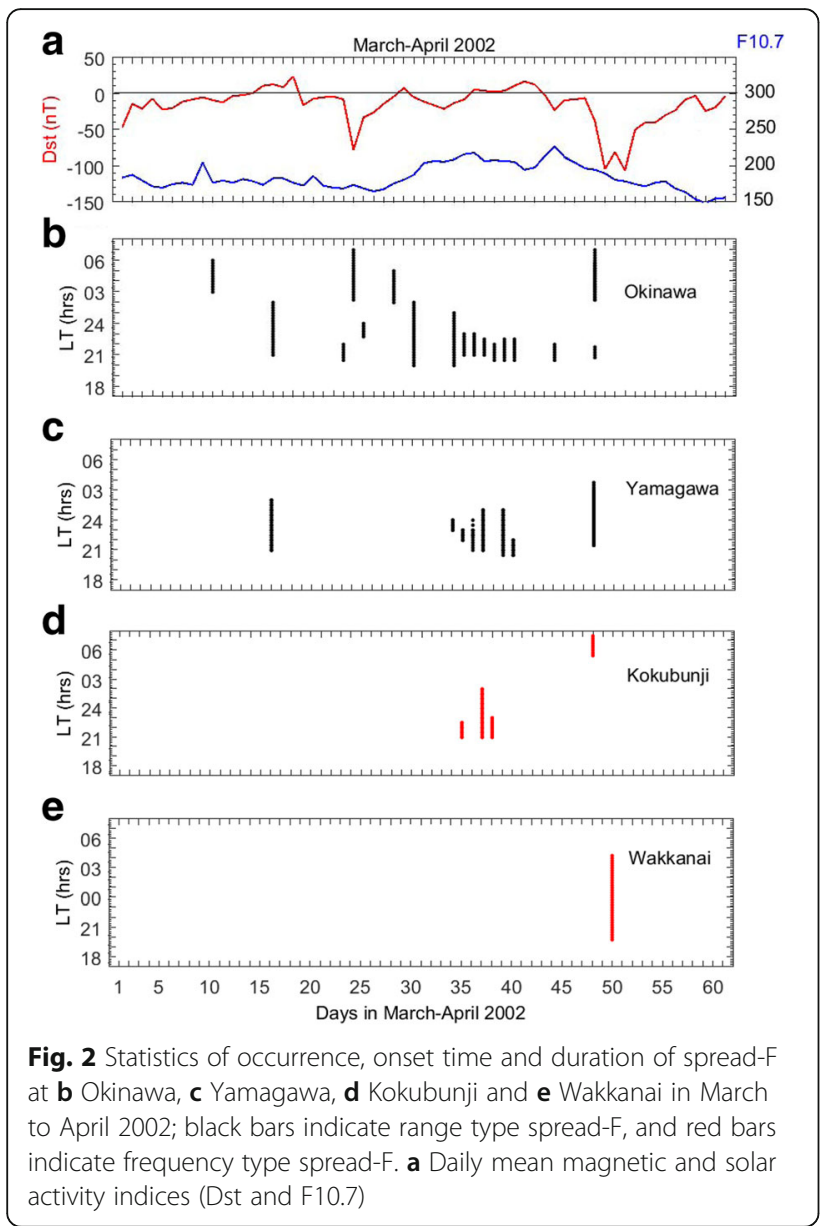

crest at magnetic latitudes near $25^{\circ} \mathrm{N}$ in Japan longitudes; spread-F at the equatorward side of the minimum is mainly of equatorial origin, and at the poleward side of the minimum, there is almost no spread-F, discussed below.

\section{Medium solar activity}

Spread-F occurs more frequently at medium solar activity (2003; Fig. 3) than at high solar activity at all locations especially at higher latitudes. Compared to high solar activity while the occurrence increases by about $12 \%$ at low latitudes $\left(17.0^{\circ} \mathrm{N}\right.$, Okinawa), the increase is over $55 \%$ at mid latitudes $\left(36.5^{\circ} \mathrm{N}\right.$, Wakkanai) and the increase at the latitudes in between is $15 \%$ at $21.2^{\circ} \mathrm{N}$ and $30 \%$ at $26.5^{\circ} \mathrm{N}$. More importantly, in 2003 (Fig. 3), the occurrence shows a clear minimum near Yamagawa $\left(21.2^{\circ} \mathrm{N}\right)$ while it was near Kokubunji $\left(26.5^{\circ} \mathrm{N}\right)$ in 2002 . The occurrence also indicates a possible maximum near or beyond Wakkanai $\left(36.5^{\circ} \mathrm{N}\right)$ while there was almost no spread-F beyond the minimum in 2002. The onset time of spread-F varies from as early as 18:00 LT to as late as 04:30 LT with over half of the onsets being after 21-22 LT at all locations. The duration of spread $\mathrm{F}$ varies from as short as $30 \mathrm{~min}$ to as long as $11 \mathrm{~h}$ with about half of the cases lasting over $5 \mathrm{~h}$.

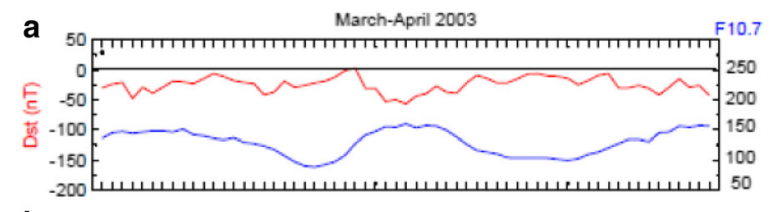

b

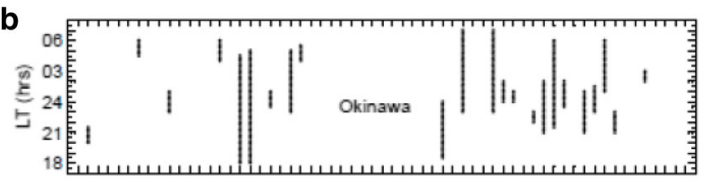

C

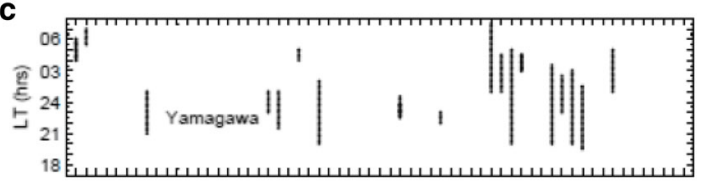

d

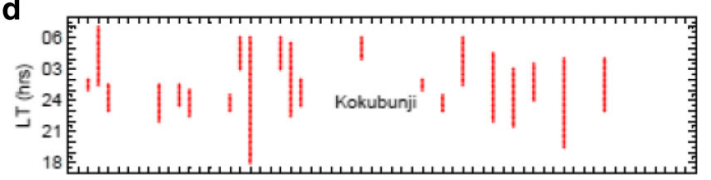

e

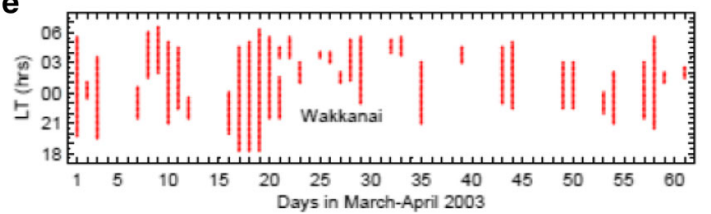

Fig. 3 Statistics of occurrence, onset time and duration of spread-F at b Okinawa, c Yamagawa, d Kokubunji and e Wakkanai in March to April 2003; black bars indicate range type spread-F, and red bars indicate frequency type spread-F. a Daily mean magnetic and solar activity indices (Dst and F10.7)

The observations therefore indicate that at medium solar activity, there is a clear spread-F minimum located at $\sim 20^{\circ} \mathrm{N}$ mag. lat. at the poleward side of the typical EIA crest that reaches as far as $\sim 18^{\circ} \mathrm{N}$ (Balan and Bailey $1995)$. There is also indication of a spread-F maximum at $\sim 35^{\circ} \mathrm{N}$ mag. lat. (Wakkanai) or beyond as expected (Eq. 2), and the spread-F at the poleward side of the minimum (Kokubunji and Wakkanai) is mainly of midlatitude mechanism.

\section{Low solar activity}

The spread-F occurrence is most frequent at low solar activity (2006; Fig. 4) at all locations except at the highest latitude (Wakkanai) where it slightly decreases by $8 \%$ compared to medium solar activity. With respect to medium solar activity, while the occurrence increases by $20 \%$ at Okinawa, the increase is $36 \%$ each at Yamagawa and Kokubunji. It is interesting to note that the occurrence in 2006 is least frequent at Okinawa $\left(17.0^{\circ} \mathrm{N}\right)$ and most frequent and almost equally at Yamagawa and Kokubunji $\left(21.2^{\circ} \mathrm{N}\right.$ and $\left.26.5^{\circ} \mathrm{N}\right)$. The onset time is generally after 22 LT at all locations except at Wakkanai where some cases started before 22 LT. The duration of spread-F is generally 


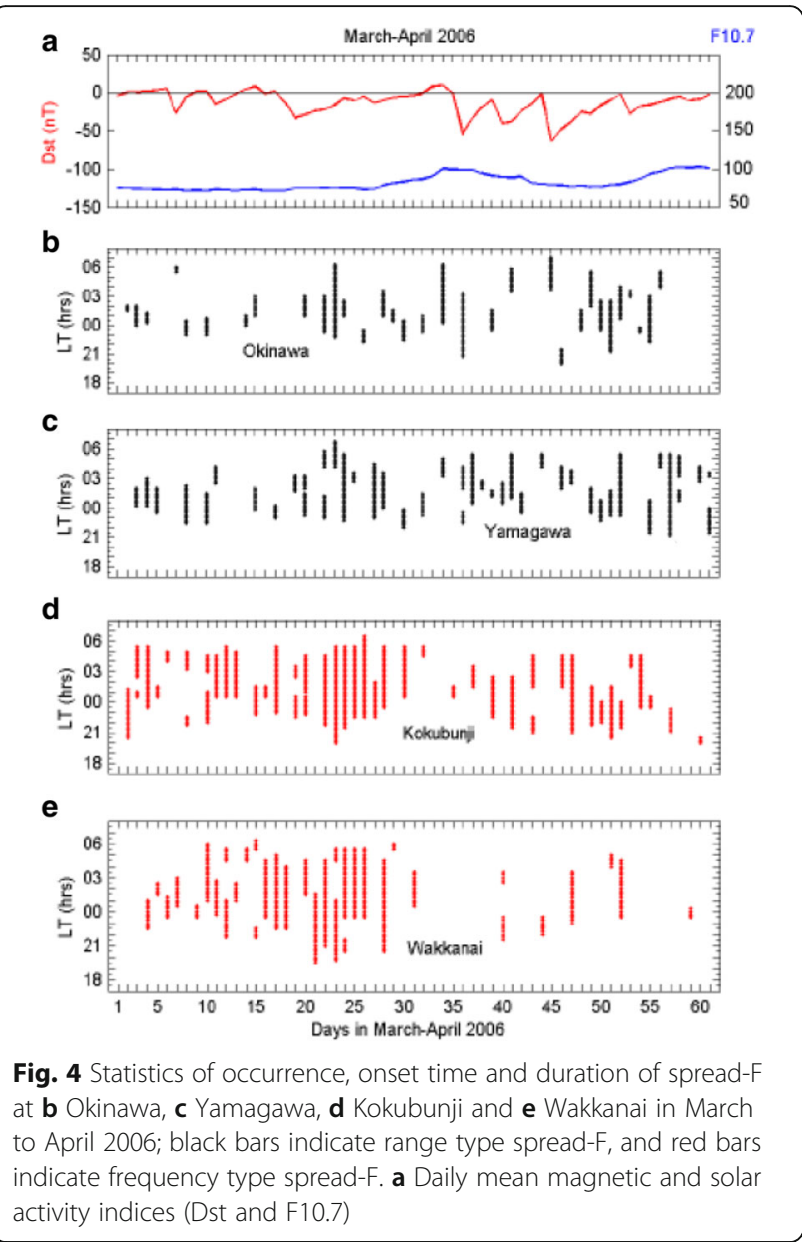

longer at higher latitudes. These observations indicate that the spread-F minimum at low solar activity might be located at latitudes below $17^{\circ} \mathrm{N}$ when a weak EIA crest reaches up to $\sim 15^{\circ} \mathrm{N}$ (Balan et al. 2012). There is also a clear spread-F maximum located at $\sim 20^{\circ}-25^{\circ} \mathrm{N}$ mag. lat., and the spread-F at all locations (now on the poleward of the minimum) is mainly of mid-latitude mechanism.

\section{Magnetic activity}

The data under magnetically active conditions in the selected periods are not sufficient for statistical study. At high solar activity (Fig. 2), an intense magnetic storm (DstMin up to - $149 \mathrm{nT}$ ) with multiple dips in Dst occurred. Spread-F occurred during the first main phase at all three lower latitude locations with earlier onset at lower latitudes as shown by the horizontal bars in Fig. 5 . The characteristics of the spread-F indicate that the irregularity might have been caused by the eastward electric field penetrated from high to low latitudes. Several moderate storms occurred both at medium and low solar activities (Figs. 3 and 4), though no storm-related spread-F can be identified. It is interesting to note that the lone spread$\mathrm{F}$ observed at the highest latitude location (Wakkanai) at

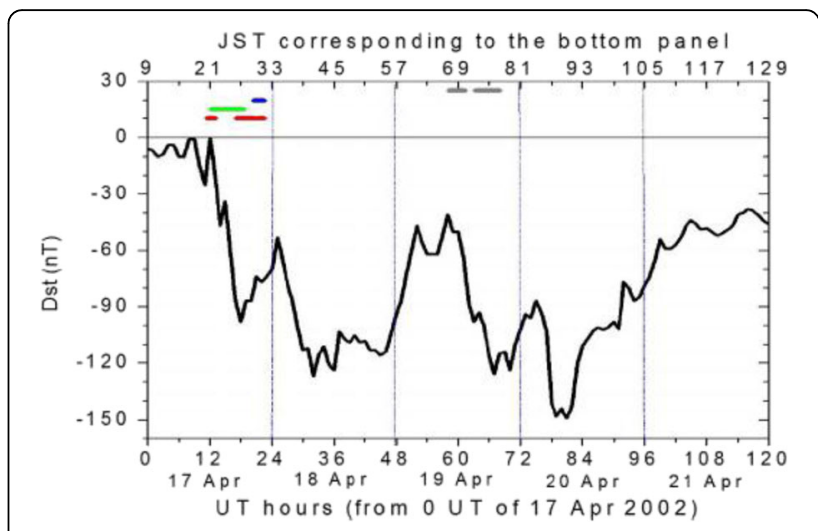

Fig. 5 Dst variation and occurrence of spread-F during a multiple geomagnetic storm with first main phase on 17 April 2002. Spread-F occurrences are indicated by thick horizontal lines (red for Okinawa, green for Yamagawa, blue for Kokubunji and grey for Wakkanai)

high solar activity (Fig. 2) occurred during the middle of the long storm (Fig. 5) with no spread-F at lower latitudes. The strong spread-F started at $\sim 19.5 \mathrm{LT}$ and lasted for over $9 \mathrm{~h}$ which could most probably be due to stormrelated MSTIDs originated at high latitudes.

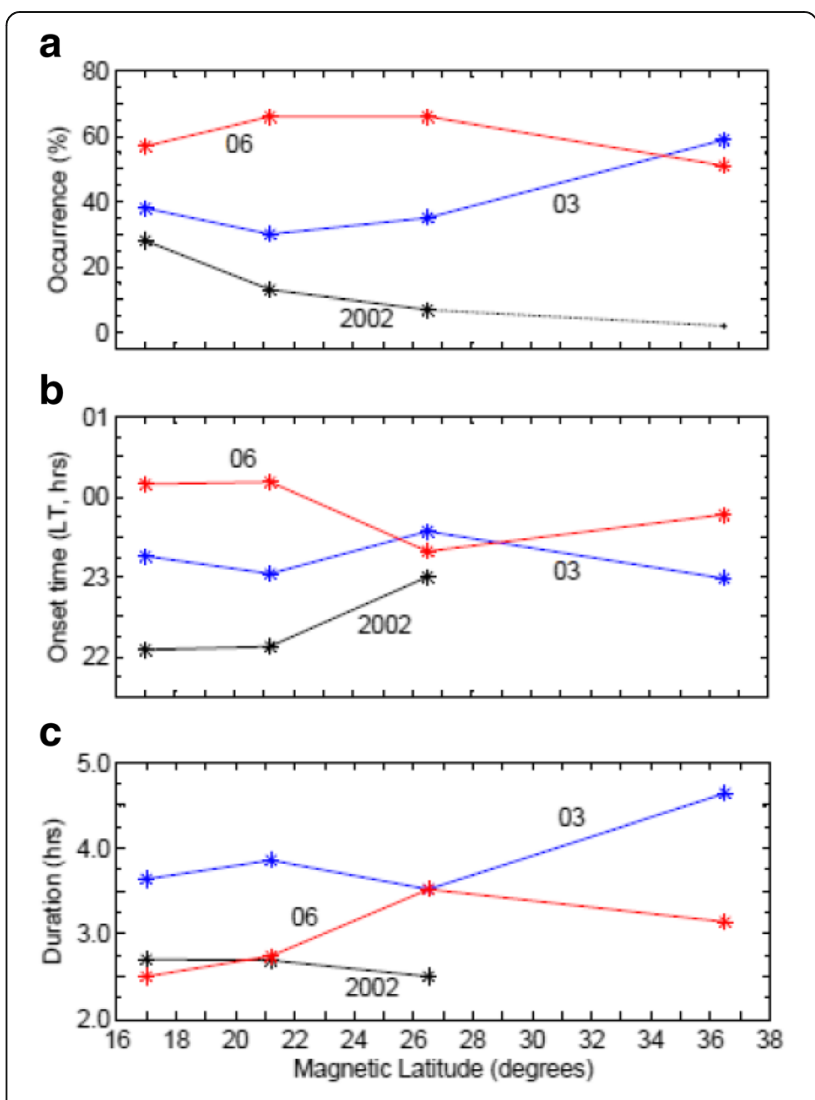

Fig. 6 Latitude variations of a percentage of days of spread-F occurrence, b mean onset time of spread- $F$, and $\mathbf{c}$ mean duration of spread-F in 2002 (black), 2003 (blue) and 2006 (red). The onset time and duration of the lone case at $36.5^{\circ} \mathrm{N}$ (Wakkanai) in 2002 are not plotted 


\section{Discussion}

The statistics of occurrence, onset time and duration of spread-F are summarised in Fig. 6. As shown, the spread-F occurrence (Fig. 6a) at all locations increases with decreasing solar activity particularly at higher latitudes $\left(26.5^{\circ}-36.5^{\circ} \mathrm{N}\right)$ where the occurrence increases from a low of $\sim 2 \%$ at high solar activity to a high of over $65 \%$ at low solar activity. The onset time of spreadF (Fig. 6b) at low latitudes $\left(<25^{\circ} \mathrm{N}\right.$ mag. lat.) shifts from post-sunset at high solar activity to post-midnight at low solar activity, and at higher latitudes, the onset occurs at around the same time (before mid-night) at all levels of solar activity. The duration of spread-F (Fig. 6c) is long at medium solar activity. The latitude variation of spread-F occurrence is similar to that of night-time anomalous enhancement in total electron content that exhibits a distinct low latitude minimum bounded by maxima on either side (e.g. Balan and Rao 1987).

As described in the "Introduction" section, the plasma irregularities at March equinox manifesting as spread-F in ionograms are caused by separate mechanisms at equatorial (up to EIA crest) and higher latitudes, though there are overlaps at the latitude boundary. At equatorial latitudes, the irregularities originate in the bottomside Flayer mainly through the RT instability mechanism driven by PRE (e.g. Patra 2008; Yokoyama and Stolle 2017). At higher latitudes, the irregularities are known to be caused by the Perkins instability mechanism (Perkins 1973). Theoretical calculations of the latitude variation of the irregularities due to the RT mechanism have predicted a minimum at around $18^{\circ}$ mag. lat. at March equinox at medium solar activity (e.g. Maruyama 1990). The ionosonde data at March equinox under three levels of solar activity analysed in this paper specifically to identify the expected minimum have brought out the minimum and showed that the minimum shifts to lower latitudes with decreasing solar activity. The analysis has also identified a spread-F maximum on the poleward side of the minimum expected from the Perkins mechanism (e.g. Tsunoda 2006); the maximum also shifts equatorward with decreasing solar activity.

In addition to the latitude variation of the RT mechanism that predicted the existence of the spread-F minimum (e.g. Maruyama 1990), the low latitude limit of the Perkins mechanism driven by MSTIDs (Shiokawa et al. 2002) also supports the existence of the spread-F minimum. The optical observations of MSTID propagation (Shiokawa et al. 2002) showed a low latitude limit for the propagation at around $18^{\circ} \mathrm{N}$ mag. lat. The spread-F observations (Fig. 3) under similar conditions (March equinox at medium solar activity) indicate the minimum occurring at $\sim 20^{\circ} \mathrm{N}$ mag. lat. at the poleward side of the EIA crest. The spread-F minimum shifts from $\sim 25^{\circ} \mathrm{N}$ mag. lat. at high solar activity to below $17^{\circ} \mathrm{N}$ at low solar activity (Figs. 2, 3, 4, 5 and 6) when the typical location of the EIA crest shifts from $\sim 22^{\circ} \mathrm{N}$ to $15^{\circ} \mathrm{N}$. The spread-F maximum occurring on the poleward side of the minimum (under medium and low solar activities) also shifts equatorward with decreasing solar activity. There is almost no spread-F on the poleward side of the minimum at high solar activity.

As mentioned, the spread-F occurrence (Figs. 2, 3, 4, 5 and 6) on the poleward side of the minimum seems mainly of local origin. The local origin believed to be due to Perkins mechanism (Perkins 1973) is associated well with nighttime MSTIDs because (1) like spread-F, MSTIDs also occur most frequently at low solar activity and least frequently at high solar activity (Shiokawa et al. 2002, 2003), and (2) the low latitude limit of MSTIDs extends to further lower latitudes with decreasing solar activity (Narayanan et al. 2014b). These features of MSTIDs agree well with the observed spread-F occurrence on the poleward side of its minimum. Shiokawa et al. (2003) who studied the spread-F at mid latitudes reported $\sim 10 \%$ occurrence of spread-F during the high solar activity period spanning 4 years (1979-1982), which also agrees with the present observations of $\sim 2 \%$ at the peak of solar activity (1982).

Since the purpose of the present paper is to identify the latitude of the spread-F minimum expected at March equinox, we used the data at same equinox season. It will be interesting to do a similar study at solstices as well, which we plan to undertake in the near future. Earlier, Shiokawa et al. (2003) presented the monthly variation of spread-F occurrence at the four locations under high and low solar activity conditions. They showed that the spread-F occurrence reaches a maximum in summer months.

\section{Conclusions}

The short paper has presented the statistics of spread-F occurrence at four low-mid latitude locations $\left(17.0^{\circ} \mathrm{N}\right.$, $21.2^{\circ} \mathrm{N}, 26.5^{\circ} \mathrm{N}$ and $36.5^{\circ} \mathrm{N}$ mag. lat.) in Japan $\left(\sim 135^{\circ}\right.$ E) in March to April 2002, 2003 and 2006. The important observations are listed.

- The spread-F occurrence increases with decreasing solar activity especially at latitudes greater than $25^{\circ} \mathrm{N}$ mag. lat.

- The location of a spread-F minimum predicted by theoretical models is identified for the first time.

- The spread-F minimum occurs at the poleward side of the EIA crest and shifts from $\sim 25^{\circ} \mathrm{N}$ at high solar activity to below $17^{\circ} \mathrm{N}$ at low solar activity.

- The corresponding spread-F maximum occurring on the poleward side of the minimum (at low and medium solar activities) also shifts equatorward from $\sim 35^{\circ} \mathrm{N}$ (or beyond) to $20^{\circ}-25^{\circ} \mathrm{N}$.

- There is almost no spread-F on the poleward side of the minimum at high solar activity. 


\section{Acknowledgements}

N. Balan thanks T. Maruyama for inviting him to NICT under JSPS invitation fellowship in 2003 when this study was initiated, and IGGCAS of China and ISEE of Nagoaya University for visiting professor positions. V.L.N. is supported by the INSPIRE Faculty grant IFA14/EAS18 from the Department of Science and Technology, Govt. of India. The ionosonde data used are obtained using the ionosondes in Japan, which are available at http://wdc.nict.go.jp/ionog/ js_viewer/js_01.html.

\section{Funding}

No funding is available for this paper.

\section{Availability of data and materials}

The data used are obtained using the ionosondes in Japan, which are available at http://wdc.nict.go.jp/ionog/js_viewer/js_01.html.

\section{Authors' contributions}

NB took the initiative, analysed the data and prepared the paper. TM provided the data. AKP has been involved in the discussions. VLN did some data analysis and participated in the discussions. All authors read and approved the final manuscript.

\section{Ethics approval and consent to participate} Not applicable.

\section{Consent for publication}

Not applicable.

\section{Competing interests}

The authors declare that they have no competing interests.

\section{Publisher's Note}

Springer Nature remains neutral with regard to jurisdictional claims in published maps and institutional affiliations.

\section{Author details}

'Institute of Geology and Geophysics, Chinese Academy of Sciences, Beijing 100029, China. ${ }^{2}$ Institute of Space Earth Environment, Nagoya University, Nagoya, Japan. ${ }^{3} \mathrm{NICT}$, 4-2-1 Nakui Kitamachi, Tokyo 184-8795, Japan.

${ }^{4}$ National Atmospheric Research Laboratory, Gadanki, India.

\section{Received: 4 August 2017 Accepted: 21 March 2018}

Published online: 02 May 2018

\section{References}

Aarons J (1993) The longitudinal morphology of equatorial F layer irregularities relevant to their occurrence. Space Sci Rev 63:209-243

Abdu MA, de Souza JR, Kherani EA, Batista IS, MacDougall JW, Sobral JHA (2015) Wave structure and polarization electric field development in the bottomside F layer leading to post-sunset equatorial spread F. J Geophys Res 120: 6930-6940

Balachandran R, Balan N, Bailey GJ, Rao PB (1992) Spectra of the ac electric fields in the post sunset $F$ region at the magnetic equator. Planet Space Sci 40:655

Balan N, Bailey GJ (1995) Equatorial plasma fountain and its effects: possibility of an additional layer. J Geophys Res 100:21,421

Balan N, Bailey GJ, Abdu MA, Oyama Kl, Richards PG, Macdougall J, Batista IS (1997) Equatorial plasma fountain and its effects over three locations: evidence for an additional layer, the F3 layer. J Geophys Res 102:2047

Balan N, Chen CY, Rajesh PK, Liu JY, Bailey GJ (2012) Modeling and observations of the low latitude ionosphere-plasmasphere system at long deep solar minimum. J Geophys Res 117:A08316. https://doi.org/10.1029/2012JA017846

Balan N, Jayachandran B, Balachandran Nair R, Namboothiri SP, Bailey GJ, Rao PB (1992) HF Doppler observations of vector plasma drifts in the evening F region at the magnetic equator. J Atmos Terr Phys 54:1545

Balan N, Rao PB (1987) Latitudinal variations of nighttime enhancements in total electron content. J Geophy Res 92:3436

Booker HG, Wells HW (1938) Scattering of radio waves by the F region of the ionosphere. J Geophys Res 43:249

Bowman GG (1990) A review of some recent work on mid-latitude spread-F. J Geomagn Geoelectr 42:109-138
Dungey JW (1956) Convective diffusion in the equatorial F region. J. Atmos. Terr. Phys. 9:304-310

Eccles JV, St. Maurice JP, Schunk RW (2015) Mechanisms underlying the prereversal enhancement of the vertical plasma drift in the low-latitude ionosphere. J Geophys Res 120:4950-4970

Fejer BG, Farley DT, Woodman RF, Calderon C (1979) Dependence of equatorial F region vertical drfits on season and solar cycle. J Geophys Res 84:5792

Fukao S, Kelley MC, Shirakawa T, Takami T, Yamamoto M, Tsuda T, Kato S (1991) Turbulent upwelling of the mid latitude ionosphere 1. Observational results by the MU radar. J Geophys Res 96:3725

Hamza AM (1999) Perkins instability revisited. J Geophys Res 104:22567-22575

Heelis RA, Kendall PC, Moffett RJ, Windle W, Rishbeth H (1974) Electrical coupling of the $E$ and $F$ regions and its effects on $F$ region drifts and winds. Planet Space Sci 22:743

Huang C-S, Hairston MR (2015) The postsunset vertical plasma drift and its effects on the generation of equatorial plasma bubbles observed by the C/NOFS satellite. J Geophys Res 120:2263-2275. https://doi.org/10.1002/2014JA020735

Jayachandran B, Balan N, Rao PB, Sastri JH, Bailey GJ (1993) HF Doppler and ionosonde observations on the onset conditions of equatorial spread- $F$. J Geophys Res 98:13741

Kelley MC, Fukao S (1991) Turbulent upwelling of the mid latitude ionosphere 2. Theoretical framework. J Geophys Res 96:3747

Kelley MC, Makela JJ, de La Beaujardière O, Retterer J (2011) Convective ionospheric storms: a review. Rev Geophys 49:RG2003. https://doi.org/10. 1029/2010RG000340

Makela JJ, Otsuka Y (2012) Overview of nighttime ionospheric instabilities at lowand mid-latitudes: coupling aspects resulting in structuring at the mesoscale. Space Sci Rev 168:419-440. https://doi.org/10.1007/s11214-011-9816-6

Maruyama T (1990) ExB instability in the F region at low to mid latitudes. Planet. Space. Sci. 38:273

Maruyama T, Matuura N (1984) Longitudinal variability of annual changes in activity of equatorial spread F and plasma bubbles. J Geophys Res 89:10,903

Miller, C. A., Electrodynamics of midlatitude spread F 2. A new theory of gravity wave electric fields, J Geophys Res., 102, doi:https://doi.org/10.1029/96JA03840, 1997

Namboothiri SP, Balan N, Rao PB (1989) Vertical plasma drift in the F-region at the magnetic equator. J Geophys Res 94:12055

Narayanan VL, Shiokawa K, Otsuka Y, Saito S (2014a) Airglow observations of nighttime medium-scale traveling ionospheric disturbances fromYonaguni: statistical characteristics and low-latitude limit. J Geophys Res 119. https:// doi.org/10.1002/2014JA020368

Narayanan VL, Sukanta Sau S, Gurubaran K, Shiokawa N, Balan K, Emperumal S, Sripathi (2014b) A statistical study of satellite traces and evolution of equatorial spread F. Earth Planets Space 66:160. https://doi.org/10.1186/ s40623-014-0160-4

Nishioka M, Otsuka Y, Shiokawa K, Tsugawa T, Effendy P, Supnithi T, Nagatsuma K, Murata T (2012) On post-midnight field-aligned irregularities observed with a 30.8-MHz radar at a low latitude: comparison with F-layer altitude near the geomagnetic equator. J Geophys Res 117:A08337. https://doi.org/ 10.1029/2012JA017692

Ossakow SL (1981) Spread F theories-a review. J. Atmos. Terr. Phys. 43:437

Otsuka Y, Shiokawa K, Ogawa T, Wilkinson P (2002) Geomagnetic conjugate observations of equatorial airglow depletions. Geohys Res Let 29. https://doi. org/10.1029/2002GL015347

Patra AK (2008) Some aspects of electrostatic coupling between E and F regions relevant to plasma irregularities: a review based on recent observations. J Atmos Solar Terr Phys 70:2159-2171

Patra AK, Taori A, Pavan Chaitanya P, Sripathi S (2013) Direct detection of wavelike spatial structure at the bottom of the $\mathrm{F}$ region and its role on the formation of equatorial plasma bubble. J Geophys Res 118. https://doi.org/ 10.1002/jgra.50148

Perkins F (1973) Spread F and ionospheric currents. J Geophys Res 78:218-226

Saito A et al (2001) Traveling ionospheric disturbances detected in the FRONT campaign. Geophys Res Lett 28:689-692

Scannapieco AJ, Ossakow SL (1976) Nonlinear equatorial spread F. Geophys Res Lett 3:451

Sekar R, Suhasini R, Raghavarao R (1995) Evolution of plasma bubbles in the equatorial $F$ region with different seeding conditions. Geophys Res Lett 22:885

Shiokawa K, Otsuka Y, Ihara C, Ogawa T, Rich FJ (2003) Ground and satellite observations of nighttime medium-scale traveling ionospheric disturbances at midlatitude. J Geophys Res 108(A4):1145. https://doi.org/10.1029/ 2002JA009639 
Shiokawa K et al (2002) Imaging observations of the equatorward limit of midlatitude traveling ionospheric disturbances. Earth Planets Space 54:57-62

Tsunoda RT (2006) On the coupling of layer instabilities in the nighttime midlatitude ionosphere. J Geophys Res 111:A11304. https://doi.org/10.1029/ 2006JA011630

Tsunoda RT, Bubenik DM, Thampi SV, Yamamoto M (2010) On large-scale wave structure and equatorial spread $F$ without a post-sunset rise of the $F$ layer. Geophys Res Lett 37:L07105. https://doi.org/10.1029/2009GL042357

Tsunoda RT, Cosgrove RB (2001) Coupled electrodynamics in the nighttime midlatitude ionosphere. Geophys Res Lett 28:4171-4174

Tulasiram S et al (2014) Characteristics of large-scale wave structure observed from African and Southeast Asian longitudinal sectors. J Geophys Res 119. https://doi.org/10.1002/2013JA019712

Whalen JA (2002) Dependence of equatorial bubbles and bottomside spread $F$ on season, magnetic activity, and ExB drift velocity during solar maximum. J Geophys Res 107. https://doi.org/10.1029/2001JA000039

Woodman RF (2009) Spread F-an old equatorial aeronomy problem finally resolved? Ann Geophys 27:1915-1934

Woodman RF, La Hoz C (1976) Radar observations of F region equatorial irregularities. J Geophys Res 81:5447

Yokoyama T, Otsuka Y, Ogawa T, Yamamoto M, Hysell DL (2008) First threedimensional simulation of the Perkins instability in the nighttime midlatitude ionosphere. Geophys Res Lett 35:L03101. https://doi.org/10.1029/ 2007GL032496

Yokoyama T, Stolle C (2017) Low and midlatitude ionospheric plasma density irregularities and their effects on geomagnetic field. Space Sci Rev 206:495-519. https://doi.org/10.1007/s11214-016-0295-7

\section{Submit your manuscript to a SpringerOpen ${ }^{\odot}$ journal and benefit from:}

- Convenient online submission

- Rigorous peer review

- Open access: articles freely available online

- High visibility within the field

- Retaining the copyright to your article

Submit your next manuscript at $\gg$ springeropen.com 